\title{
GESTATIONAL THROMBOCYTOPENIA: MATERNAL AND FETAL OUTCOMES IN DUHOK
}

\author{
SHANG M. S. SADULLA; KBMS OBSTETRICS \& GYNECOLOGY* \\ ALAA Y. MAHMOOD; M.B.CH.B., MRCOG, OBSTETRICS \& GYNECOLOGY** \\ MAIDA YOUSIF SHAMDEEN; PROF. MRCOG/FRCOG***
}

Submitted 20 April 2020; accepted 13 September 2020

\begin{abstract}
Background: Thrombocytopenia (platelet counts less than $150 \mathrm{X} 10^{9} / \mathrm{L}$ ), is a common hematological finding during pregnancy ranking secondly after anemia. This study aimed to examine possible contributing factors to the low platelet count in pregnant women with thrombocytopenia during their intrapartum period and the maternal and fetal outcomes.

Patients and Methods: A total of 33,476 women with a singleton pregnancy with a gestational age of 28 weeks and beyond were admitted to the labor ward at Duhok obstetrics and gynecology hospital between May 2015 and January 2018. Applying the hospital routine admission protocol, the platelet count of each of them was estimated and a total of 802 thrombocytopenic cases were selected. All patients denied any previous related medical or obstetric histories: like hypertensive diseases of pregnancy, connective tissue disorders, immune thrombocytopenia, liver or renal disease, and drug-induced thrombocytopenia. Maternal and fetal outcomes were assessed to see if there are any risks of this incidental finding on their health.
\end{abstract}

Results: The study found that most of the patients did not needed blood or platelet transfusions, $759(94.6 \%)$, and $788(98.3 \%)$, respectively. None of them developed any reaction to the blood transfusions. The platelet account did not affect the mode of delivery since most of them had vaginal deliveries 572 (71 \%). However, 230 ( 29\%) of them needed a cesarean section; the reason was mainly due to obstetrical causes (failure of progress of labor, fetal distress, oligohydramnios, breech presentation, and more than one previous scar presented in labor). Most of the patients with a significant low platelet count $(\leq 50 \mathrm{X} 109 / \mathrm{L})$ had their newborns admitted to Neonatal Intensive Care Unit (NICU), those who received more blood or platelet transfusions had significantly lower platelet count and lower birth weights.

Conclusions: This study showed that women with markedly reduced platelet counts are more at risk, and the demand for blood and blood product transfusions is much increased, and they mostly gave birth to low birth weight babies.

Duhok Med J 2020; 14 (2): 86-96

Keywords: Blood transfusion; Low birth weight; Pregnancy complications; Thrombocytopenia.

\section{I $\begin{aligned} & \text { ematological findings during } \\ & \text { pregnancy are mostly due to iron- }\end{aligned}$} deficiency anemia, which usually ranks first, followed by thrombocytopenia, which accounts for $7-10 \%$ of cases. Normally platelet count ranges between $150 \times 10^{9} / \mathrm{L}$ $450 \times 10^{9} / \mathrm{L}$. If the count drops below $150 \times 10^{9} / \mathrm{L}, \quad$ it is considered thrombocytopenia, which is an important finding because it may indicate a serious underlying pregnancy disorder or a bleeding tendency problem undiagnosed in the mother yet. On the other hand, it could be a physiological finding, especially if the count and function are mildly affected, and fortunately, this incidental finding accounts

\footnotetext{
* Department of the Obstetrics \& Gynecology, College of Medicine, University of Duhok, Kurdistan Region, Iraq.

** Lecturer, Dep. of the Obst. \& Gyn., College of Medicine, University of Duhok, Kurdistan Region, Iraq.

*** Professor, Dep. of the Obst. \& Gyn., College of Medicine, University of Duhok, Kurdistan Region, Iraq.

Corresponding Author: Shang M.S. Saldulla, shang.amedi90@gmail.com, Mobil +964 7504836133
} 
for $75 \%$ of the cases1. Gestational thrombocytopenia (GT), also called incidental thrombocytopenia of pregnancy, is a benign, self-limiting condition that requires no additional evaluation or treatment $^{2,3,4}$. It accounts for the vast majority of cases of thrombocytopenia discovered during pregnancy and almost all cases of thrombocytopenia in women with uncomplicated pregnancies.

GT may occur during the first trimester, but it becomes more common as gestation progresses, with the highest frequency at the delivery time, accounting for about 5 to $10 \%$. Also, GT is typically characterized as being the most common cause of isolated thrombocytopenia at the time of delivery. However, it can occur at any time during pregnancy, being mild in $99 \%$ of women, with a platelet count between (150$100 \times 10^{9} / \mathrm{L}$ ), not associated with increased bleeding or bruising tendency, isolated thrombocytopenia with no other associated abnormalities on complete blood count, and no fetal or neonatal thrombocytopenia ${ }^{7}$.

There are different causes of thrombocytopenia in pregnancy. As stated above, GT explains about $75 \%$ of all the cases, followed by hypertensive disorders that account for approximately 20\%, and immune thrombocytopenia (ITP), which is usually responsible for about $3-4 \%$. Other causes represent the remaining cases. Different theories explain the decrease in platelet count during normal pregnancy. It is thought to be due to dilution of blood under the effect of plasma expansion, which takes place at the beginning of the second trimester until term, and certainly, this finding is more exaggerated in multiple pregnancies, possibly from increased platelet clearance; as well as mean platelet volumes; platelet volume distribution width; or platelet aggregation due to high level of thromboxane A28. The mechanism(s) of GT has not been documented yet, but it may be assumed to be a physiologic adaptation of pregnancyrelated to the increased plasma volume, pooling or consumption of platelets in the placenta, or other physiologic changes that occur in uncomplicated pregnancies ${ }^{7}$.

The placenta has many vascular characteristics in common with the spleen, a major physiologic platelet sequestration site. An analysis of placental histology following 40 scheduled cesarean deliveries found that platelets were present in many areas in the perivillous fibrinoid supporting the idea that platelet sequestration and consumption in the placenta play a role in $\mathrm{GT}^{8,9}$. In GT, the platelet count is usually mildly affected; however, the function is not affected. So overall, it is not associated with maternal and fetal adverse outcomes. By contrast, significant thrombocytopenia related to medical conditions, whether it was pregnancy-related or not, can lead to adverse effects that necessitate multidisciplinary care during the antenatal period and require specific monitoring and management during the intrapartum period $^{4}$.

The current study aims to correlate incidental thrombocytopenia during the intrapartum period with maternal and fetal outcomes. This correlation will focus on women presented in labor, whether delivered vaginally or needed an urgent intervention like an emergency cesarean section because of obstetrical indication. 


\section{PATIENTS AND METHODS}

In this hospital-based retrospective analytical study, the medical files of 33476 singleton pregnant women at the time of delivery, who presented to the labor word of Duhok obstetrics and gynecology hospital between May 2015 and Jan. 2018 were reviewed. While applying the routine protocol of admission, incidental thrombocytopenia was noticed in 802 of them. All were 28 weeks and beyond pregnant women and had a negative history of any other medical diseases, their maternal and fetal outcomes were reviewed, and findings were analyzed.

\section{Data Collection}

After taking permission from the hospital administrative committee to access hard copies of the patient's medical files, case sheets of 33,476 singleton pregnant women at the time of delivery were selected and reviewed.

\section{Exclusion Criteria}

Women with essential hypertension or hypertensive diseases of pregnancy, connective tissue diseases, immune thrombocytopenia (ITP), liver diseases, renal diseases and/or drug-induced thrombocytopenia were excluded. For the initial workup, results of complete blood counts of thrombocytopenic women, antenatal data for obstetrical, past medical, drug history, and family history of thrombocytopenia or bleeding tendencies were reviewed. Documented initial assessment notes of any underlying health problems like hypertension and vaginal bleeding were noticed, leaving only 802 cases $(2.4 \%)$ of incidental thrombocytopenia to be included in the research. Points that were reviewed and included:

\section{Peripartum course}

Maternal factors:

Mode of delivery: Vaginal Delivery (VD) or Caesarean Section $(\mathrm{C} / \mathrm{S})$

Women who developed postpartum hemorrhage.

Interventions are other than regular hospital protocol granted (e.g., fetal blood sampling).

Number of patients received blood and blood products,

Adverse transfusion reactions developed (hemolytic and non-hemolytic transfusion reactions).

Fetal factors:

Fetal weight, wellbeing, and gender.

Rate of neonatal intensive care unit (NICU) admission.

\section{STATISTICAL ANALYSIS}

The demographic and clinical characteristics of patients were presented in mean and ranges. The prevalence of birth weight categories, blood and platelet transfusions, and reaction to blood transfusions were documented. A comparison of platelet counts in patients with different characteristics using independent $t$-test and One-way ANOVAwas tested. Correlation of age with platelet counts and correlation of birth weight with blood and platelet transfusions in pregnant women with thrombocytopenia was examined using Spearman's ratio test. The significant level of difference and association was determined in a $\mathrm{P}$-value of less than 0.05. The statistical package for social sciences version 25 (SPSS 25; IBM Corp; USA) was used for statistical calculations. 


\section{ETHICAL APPROVAL}

The ethical approval of the study was taken from Kurdistan Board for Medical Specialties (KBMS), and the permission letter was granted by the directorate of health and legal unit of Duhok Obstetrics and Gynecology Hospital for accessing patients' data.

\section{RESULTS}

\section{Maternal Outcomes}

In this study, 802 women from Duhok obstetrics and gynecology teaching hospital were included. The median age of the patients was 27 , ranging between 15 and 47 years, most of them were below 30 years old, as shown in (Fig. 1).

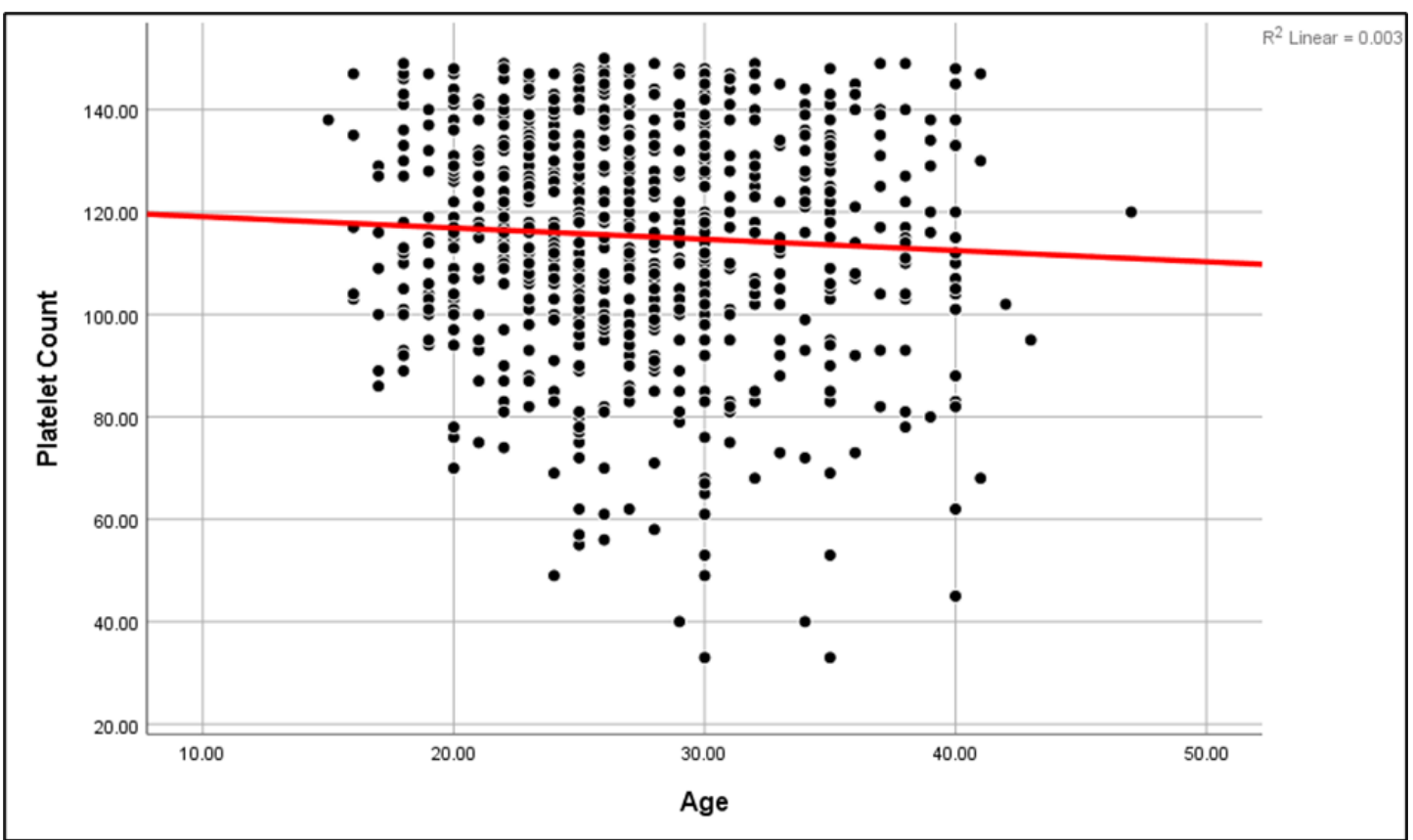

Figure 1: Correlation of age with platelet count in pregnant women with thrombocytopenia $(r=-0.031$; $P=0.381$.

The demographic characteristics of the patients are shown in, table 1 . The median value of the platelet count was 115 X 109/L ranging between $33 \mathrm{X}$ 109/L and $150 \mathrm{X}$ 109/L.

Table 1: Demographic/ clinical characteristics of patients with thrombocytopenia $(n=802)$

\begin{tabular}{lll}
\hline Patients' characteristics & Median & Range \\
\hline Age (years) & 27 & $15-47$ \\
Platelet counts & $115 \times 10^{9} / \mathrm{L}$ & $33-150 \times 10^{9} / \mathrm{L}$ \\
Neonatal Birth weight $(\mathrm{Kg})$ & 3.24 & $0.70-5.40$ \\
\hline
\end{tabular}

The severity of the thrombocytopenia cases were subdivided into three main groups. Mild thrombocytopenia (100X109/L$150 \times 109 / \mathrm{L})$ was found in $640(80 \%)$ of women, moderate thrombocytopenia
(50X109/L-100X109/L) was found in 150 $(19 \%)$, and severe thrombocytopenia $(<50 X 109 / \mathrm{L})$ was seen in $13(1 \%$.) only, Fig2. 


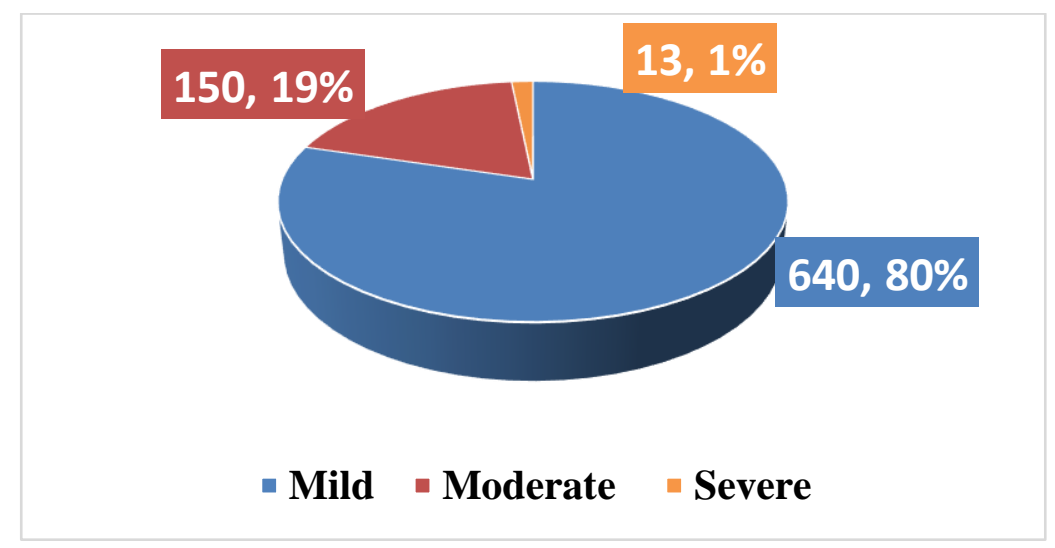

Fig 2: Distribution of the severity of thrombocytopenia among the study patients

The study revealed that $572(71.3 \%)$ of the patients had a normal vaginal delivery. In comparison, 230(28.7\%) has been delivered by cesarean section, most commonly due to obstetrical indications, (failure of progress of labor, fetal distress, oligohydramnios, breech presentation and women with more than one scar presenting in labor). Postpartum hemorrhage (PPH), classified as minor PPH (500-1000 ml) and major (more than $1000 \mathrm{ml}$ ), was encountered in $31(3.9 \%)$ of the patients, with 27 (3.4\%) of them having minor, and $4(0.5 \%)$ having major PPH, despite routine active management of the third stage of labor, and 3 patients $(0.37 \%)$ developed a hematoma at the surgical site (table 2).

\begin{tabular}{lll}
\hline \multicolumn{2}{c}{ Table 2: Prevalence of Postpartum Hemorrhage in pregnant with } & thrombocytopenia \\
\hline Post Partum Hemorrhage & Frequency & Percentage \% \\
\hline Minor PPH & 27 & 3.45 \\
Major PPH & 4 & 0.5 \\
Post-operative hematoma & 3 & 0.4 \\
Total PPH cases & 31 & 3.9 \\
\hline
\end{tabular}

The study did not find any significant difference in the platelet count in patients with different modes of delivery. $(P=0.238)$ (Table 3). Most of the patients did not need blood transfusions 759 (94.6\%). Twentyone of them $21(2.6 \%)$ needed one unit, 12 $(1.5 \%)$ needed two units, $4(0.5 \%)$ needed three units, $3(0.4 \%)$ needed four units, 3 $(0.4 \%)$ needed $\geq 5$ units. Similarly, most of the patients did not needed platelet transfusions 788 (98.3\%), whereas some of the patients needed platelet transfusion; one
$(0.1 \%)$ needed 2 units; one $(0.1 \%)$ needed 3 units; seven $(0.9 \%)$ needed 4 units; four $(0.5 \%)$ needed 6 units; and one $(0.1 \%)$ needed10 units. Most patients did not react to the blood transfusion 797 (99.4\%). It has been noted that patients who received more blood and platelet transfusions had significantly lower platelet count $(P<0.001)$, table 3 . 


\begin{tabular}{|c|c|c|c|}
\hline \multirow{2}{*}{ Characteristics $(\mathrm{n}=\mathbf{8 0 2})$} & \multicolumn{2}{|c|}{ Platelet count (N X109/L) } & \multirow{2}{*}{ P-value } \\
\hline & Mean & SD & \\
\hline $\begin{array}{l}\text { Delivery } \\
\text { VD } \\
\text { C/S }\end{array}$ & $\begin{array}{l}115.86 \\
113.86\end{array}$ & $\begin{array}{l}20.71 \\
24.00\end{array}$ & $0.238^{*}$ \\
\hline $\begin{array}{l}\text { NICU Admission } \\
\text { Yes } \\
\text { No }\end{array}$ & $\begin{array}{l}108.97 \\
115.86\end{array}$ & $\begin{array}{l}24.97 \\
21.31\end{array}$ & $0.013 *$ \\
\hline $\begin{array}{l}\text { Blood Transfusion } \\
1 \\
2 \\
3 \\
4 \\
6\end{array}$ & $\begin{array}{l}102.76 \\
106.75 \\
105.50 \\
90.33 \\
63.67\end{array}$ & $\begin{array}{l}24.68 \\
26.43 \\
20.04 \\
32.87 \\
33.50\end{array}$ & $<0.001 * *$ \\
\hline $\begin{array}{l}\text { Platelet Transfusion } \\
2 \\
3 \\
4 \\
6 \\
10\end{array}$ & $\begin{array}{l}89.00 \\
120.00 \\
77.00 \\
80.00 \\
55.00\end{array}$ & $\begin{array}{l}26.46 \\
34.79\end{array}$ & $<0.001 * *$ \\
\hline $\begin{array}{l}\text { Birth weight } \\
\text { Normal Weight } \\
\text { LBW } \\
\text { VLBW } \\
\text { VELBW }\end{array}$ & $\begin{array}{l}116.05 \\
109.82 \\
102.22 \\
94.67\end{array}$ & $\begin{array}{l}21.01 \\
24.70 \\
35.22 \\
39.55\end{array}$ & $0.011^{* *}$ \\
\hline
\end{tabular}

* Independent t-test and ** ANOVA One-way was performed for statistical analysis.

\section{Fetal outcomes}

In respect to the fetal related findings, this study has found a male to female ratio of 1.24:1 amongst all the birth outcomes. The mean birth weight was $3.24 \mathrm{Kg}$. Most of the newly born babies had normal weights 714
$(89.0 \%), 64(8.0 \%)$ of them had low birth weights (LBW), and $16(2 \%)$ had very low birth weights (VLBW), while the remaining $8(1 \%)$ had extreme low birth weight (ELBW), Fig. 3.

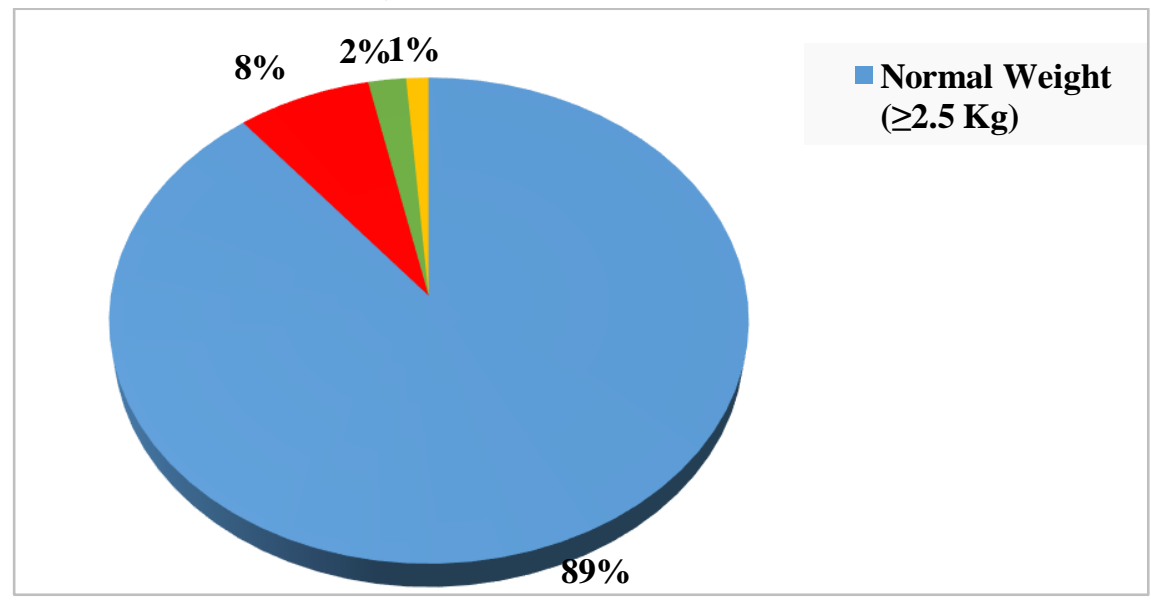

Figure 3: Neonatal Birth Weight 
Those ladies who delivered lower birth weight babies had significantly lower platelet counts $(\mathrm{P}=0.011)$ (Table 3$)$. The majority of the babies did not need NICU admission. Those admitted mostly had prematurity, respiratory distress, and low birth weight/ very low birth weight. The cause of the statistical significance was that patients whom their infants were admitted to NICU had significantly lower platelet counts than those whose infants were not admitted to the NICU (108 X 109/L vs. 115X 109/L) $P=0.013$, table 3 .

The study showed that platelet transfusion significantly decreased with increasing birth weight ( $r=-0.092, \mathrm{P}=0.01)$, Fig. 4 .

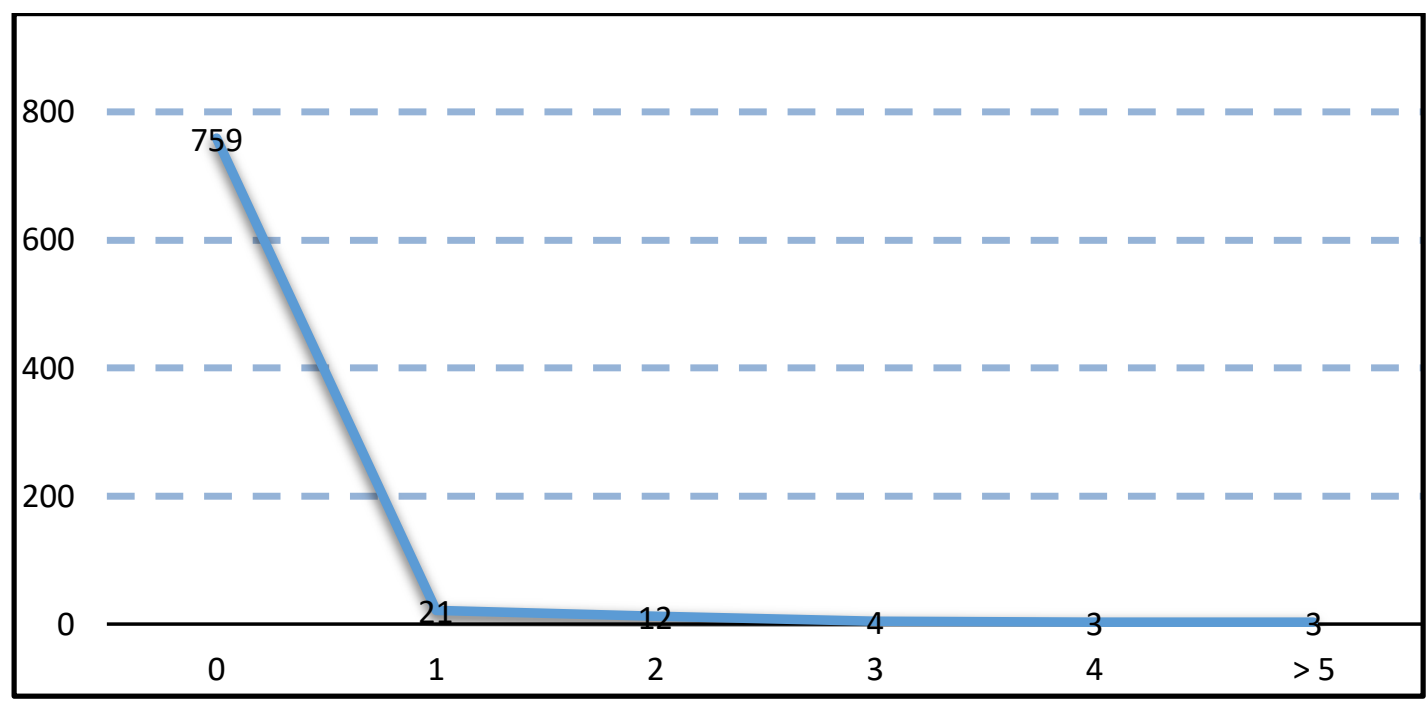

Figure 4: Patients Transfusion Needs

\section{DISCUSSION}

The study was conducted to determine the risk of incidental thrombocytopenia on mother and fetus health and whether any precautions are needed while receiving these patients unexpectedly during labor. In this study, among the thrombocytopenic pregnant women, mild thrombocytopenia was found in $80 \%$, and $19 \%$ had moderate thrombocytopenia. These results are in line with studies conducted in Ghana, India, and Nigeria $^{10,11,12}$, which showed a high frequency of mild thrombocytopenia. Such degrees of thrombocytopenia is consistent with that required for most of the obstetrical procedures to be accomplished without fear of bleeding or needing platelets transfusions ${ }^{13}$. The rate of drop in platelets count in those women with no history of platelet disorders as compared to the criteria of GT were very comparable. However, GT is a diagnosis of exclusion $^{1,14}$. In those pregnant women who were delivered vaginally $(71.3 \%)$ and undergoing active management of the third stage of labor (according to the hospital protocol), the rate of postpartum hemorrhage was $3.95 \%$ (minor $3.45 \%$, significant $0.5 \%$ ). The latter finding is an acceptable rate, according to the WHO recommendations on the prevention and treatment of postpartum hemorrhage ${ }^{14}$. For almost all those who underwent $\mathrm{C} / \mathrm{S}$, the indications were obstetrical, and only $0.3 \%$ developed surgical site hematoma. Despite different delivery modes, the study did not find any significant difference in the 
platelet count $(P=0.238)^{9}$. Most women did not need blood and blood product transfusions, but those who needed it were found to have significantly lower platelets counts $(P<0.001)$ this could be explained as the benign course of gestational thrombocytopenia ${ }^{2,9}$.

Regarding fetal outcomes, the average body weight was $3.24 . \mathrm{kg}$, with more than $90 \%$ having standard weights ${ }^{2,5,10}$, and not needing further care than initial baby resuscitation steps. Although the male to female ratio was $1.4: 1$, this study did not find any significant relationship between gender and platelet count $(P=0.291)$. Most of the admission indications were respiratory distress and prematurity. Furthermore, the study also showed that mothers of those babies who were admitted to NICU had lower platelets count compared with mothers of babies who were not admitted, and those babies who were having low birth weights had mothers with lower platelets count $(P=0.011)$. These findings raise the possibility of underlying maternal condition missed during regular antenatal care or the routine admission protocol since gestational thrombocytopenia which account for most of the cases, does not generally affect the fetal growth nor does it lead to very low maternal platelets counts $^{5,10}$, however, future researches are required to assign a special consideration to those women admitted with very low count and negative medical history to be able to diagnose the cause more specifically and monitor these babies more carefully.

\section{REFERENCES}

1. Palta A, Dhiman P. Thrombocytopenia in pregnancy .J Obstet Gynaecol. 2016; 36(2):146-152.

2. McCrae KR. Thrombocytopenia in pregnancy. Hematology Am Soc Hematol Educ Program. 2010;:397402.

3. Nelson-Piercy, Catherine. Handbook of obstetric medicine. $6^{\text {th }}$ edition. CRC press. 2020; 276-281.

4. Myers B. Thrombocytopenia in pregnancy. The obestetrician \& Gynecologist. 2009; 11: 177-183.

5. Sainio S, Kekomäki R, Riikonen S, Teramo K. Maternal thrombocytopenia at term: a population-based study. Acta Obstet GynecolScand. 2000; 79: 744-749.

6. Burrows RF, Kelton JG. Fetal thrombocytopenia and its relation to maternal thrombocytopenia. NEJM. 1993; 329: 1463.

7. Jessica A. Reese, Jennifer D. Peck, David R. Deschamps, Jennifer J. McIntosh, Eric J. Knudtson, Deirdra R. Terrell, et al. Platelet Counts during Pregnancy. NEJM. 2018; 379: 32-43.

8. Jessica A. Reese, Jennifer D. Peck, Zhongxin Yu, Teresa A. Scordino, David R. Deschamps, Jennifer J. McIntosh, et al. Platelet sequestration and consumption in the placental intervillous space contribute to lower platelet counts during pregnancy. Am J Hematol. 2019; 94:E8.

9. Burrows RF, Kelton JG. Thrombocytopenia at delivery: a prospective survey of 6715 deliveries. Am J Obstet Gynecol. 1990; 162(3): 731-734. 
10. R. Vyas, S. Shah, P. Yadav, Ushma Pate. Comparative study of mild versus moderate to severe thrombocytopenia in third trimester of pregnancy in a tertiary care hospital. NHL J Med Sci. 2014; 3 (1):8-11.

11. Fanuel Belayneh, Addis G/Mariam, Fithamlak Solomon, Zeleke Geto, Antene Amsalu, Demiss Nigussie, Et al. The prevalence of thrombocytopenia, and associated factors among pregnant women attending antenatal care at Hawassa University Referral Teaching and Hospital. J Harmoniz Res Med Hlth Sci. 2015; 2 (4): 175-182.

12. Ajibola SO, Akinbami A, Rabiu K, Adewunmi A, Dosunmu A,
Osikomaiya B. et al. Gestational thrombocytopenia women among pregnant women in Legos Nigeria. Niger Med J. 2014; 55(2): 139-143.

13. ACOG Practice Bulletin No. 207: Thrombocytopenia in Pregnancy, Obstetrics \& Gynecology: March 2019, Vol. 133, Issue 3, p. e181-e193.

14. The Prevention and Management of Postpartum Haemorrhage: Report of Technical Working Group, Geneva 36 July 1989. Geneva: World Health Organization, 1990. 


\section{يوخته}

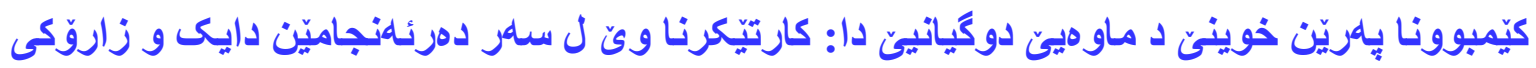

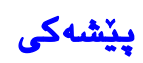

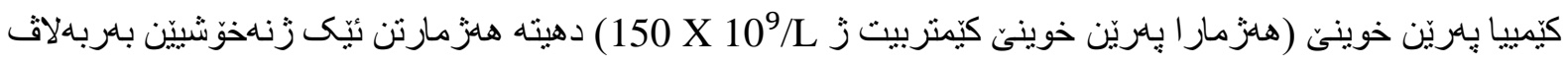

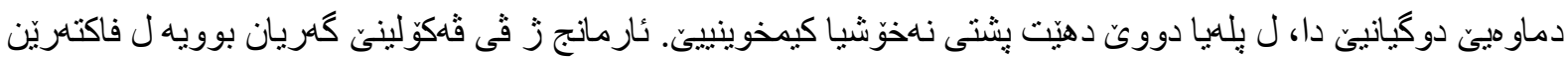

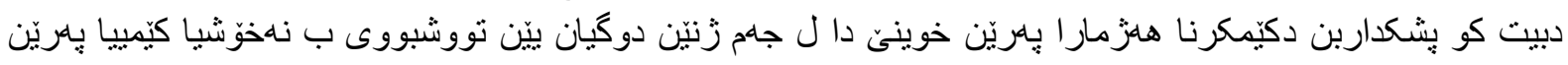

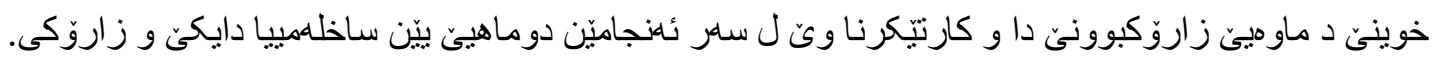

شَيْواز و نـاخوش

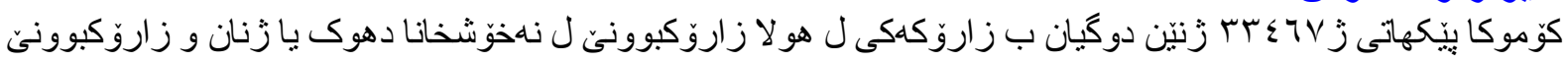

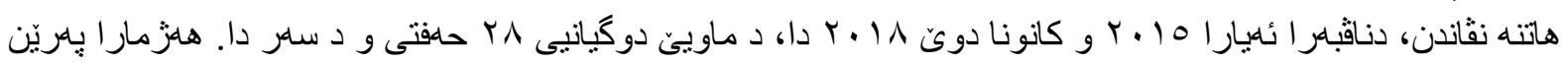

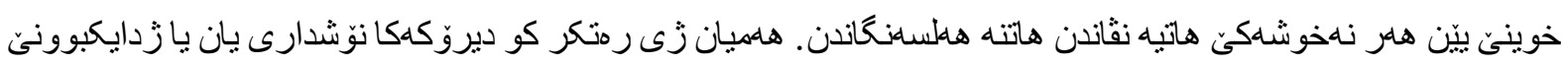

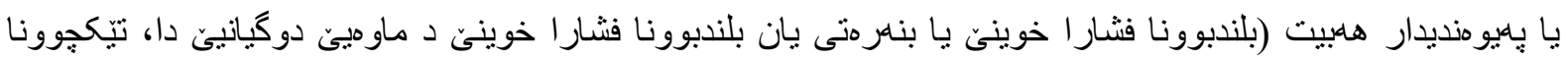

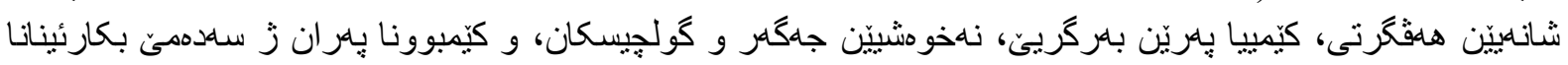

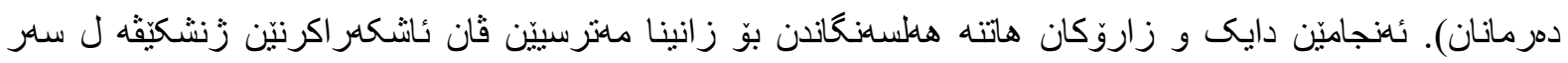
ساخلهمييا وان.

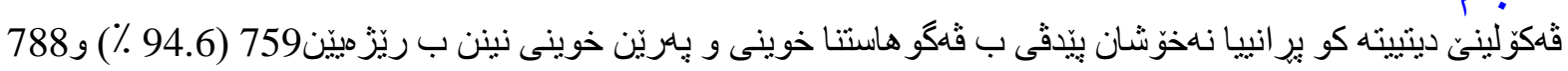

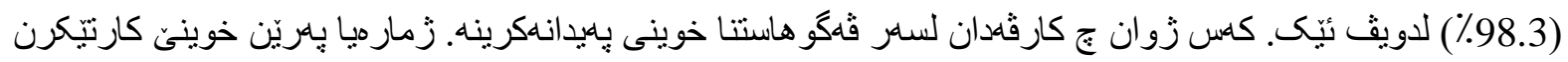

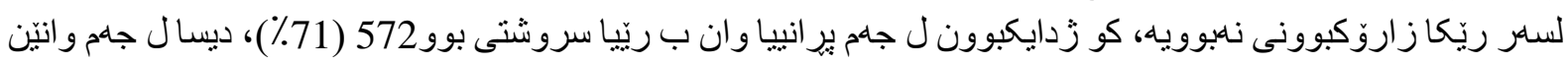

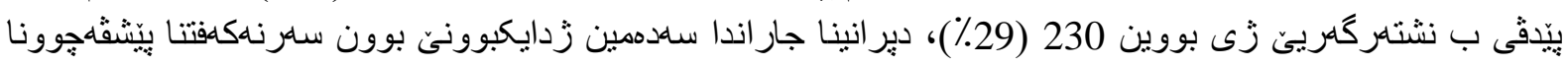

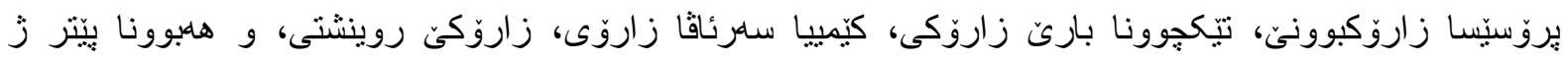

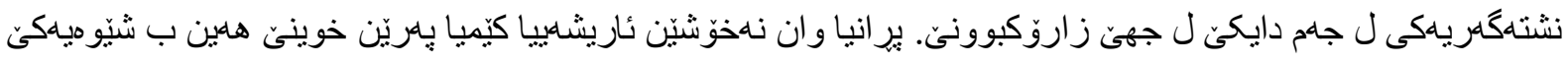

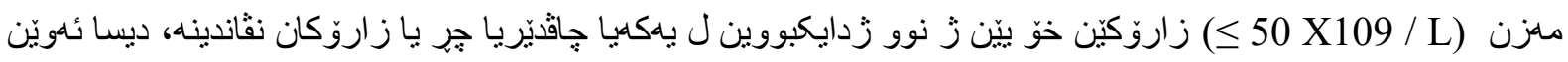

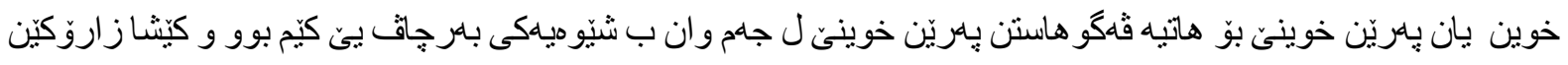

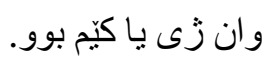

دهرئنسنجام

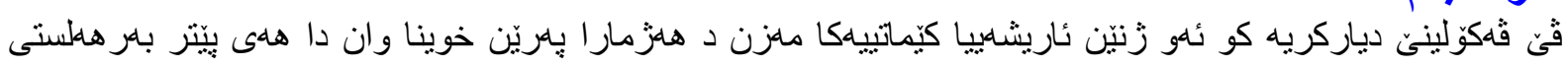

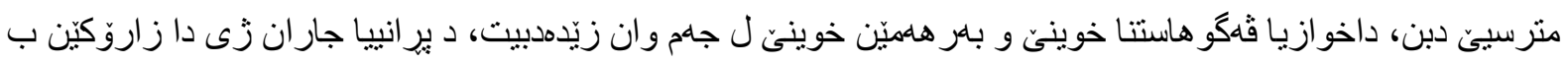




\section{الخلاصة}

\section{قلة الصفيحات الاموية أثناء الحمل: وعواقبها لاى الأمهات والأجنة في دهوك}

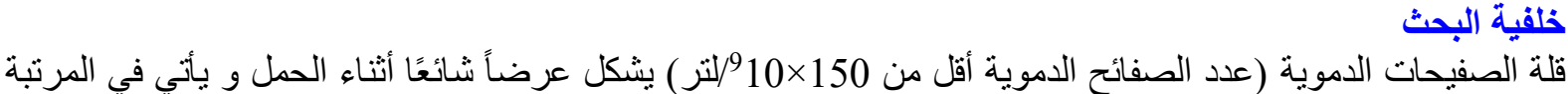

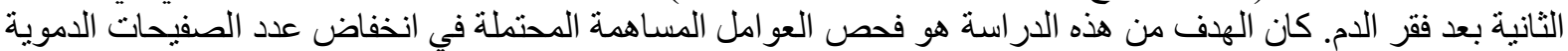

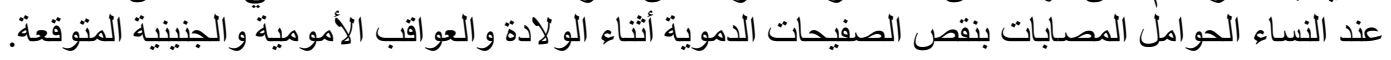

المرضى وطرق البحث

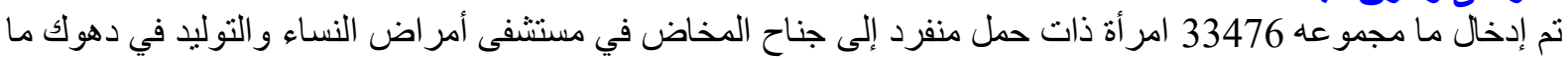

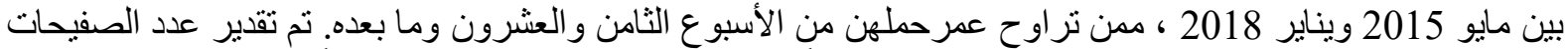

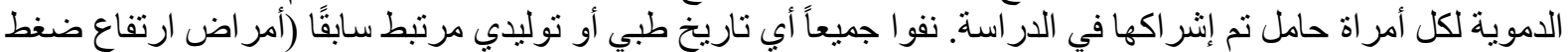

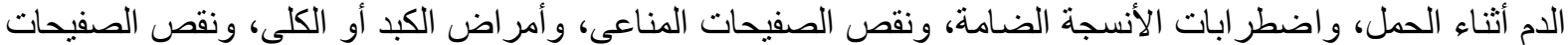
الناجم عن الأدوية). تم تقييم نتائج العواقب لألى الأم والجنين لمعرفة ما إذا كانت هنالك أية مخاطر لهذه المخرجات على الكى

صحتهم.

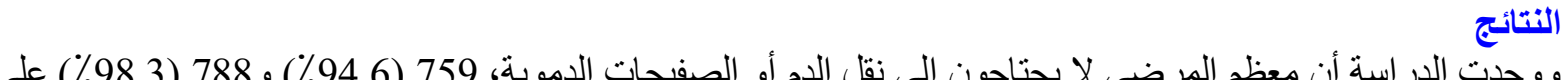

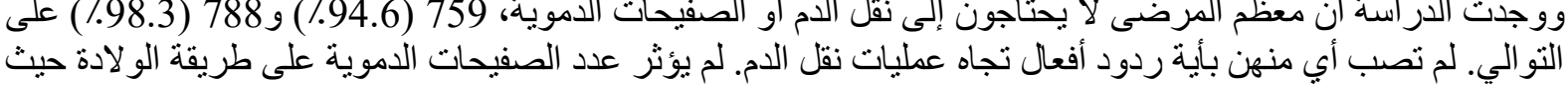

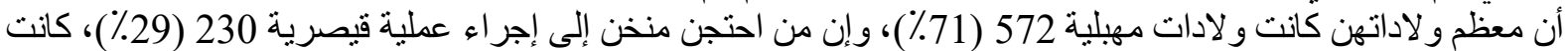

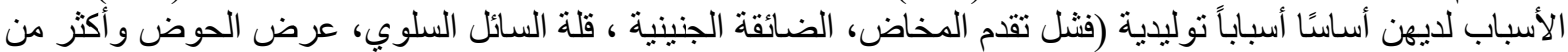

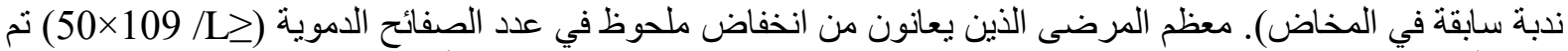

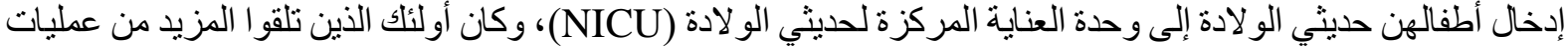

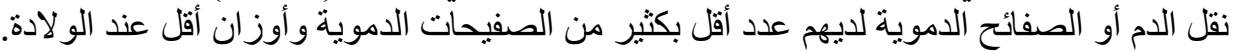

الاستنتاجات

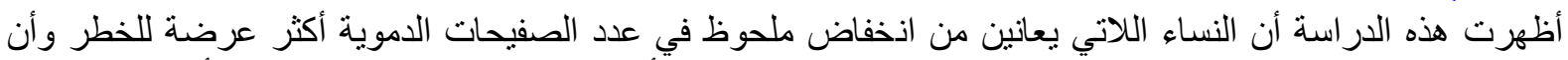

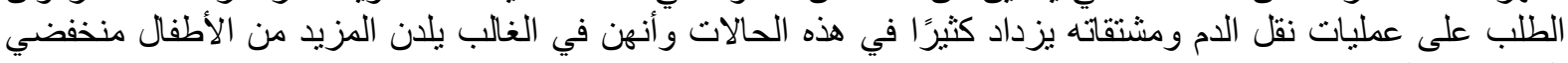
الوزن عند الو لادة. 